\title{
The Dependence of Caribbean Rainfall on the Interaction of the Tropical Atlantic and Pacific Oceans
}

\author{
DAVID B. ENFIELD \\ NOAA/Atlantic Oceanographic and Meteorological Laboratory, Miami, Florida \\ ERIC J. Alfaro \\ Department of Oceanography, University of Concepcion, Concepcion, Chile
}

(Manuscript received 26 August 1997, in final form 1 October 1998)

ABSTRACT

\begin{abstract}
Seasonally stratified analyses of rainfall anomalies over the intra-Americas sea and surrounding land areas and of onset and end dates of the Central American rainy season show that the variability of the tropical Atlantic sea surface temperature anomaly (SSTA) is more strongly associated with rainfall over the Caribbean and Central America than is tropical eastern Pacific SSTA. Seasonal differences include the importance of antisymmetric configurations of tropical Atlantic SSTA in the dry season but not in the rainy season. Both oceans are related to rainfall, but the strength of the rainfall response appears to depend on how SSTA in the tropical Atlantic and eastern Pacific combine. The strongest response occurs when the tropical Atlantic is in the configuration of a meridional dipole (antisymmetric across the ITCZ) and the eastern tropical Pacific is of opposite sign to the tropical North Atlantic. When the tropical North Atlantic and tropical Pacific are of the same sign, the rainfall response is weaker. The rainy season in lower Central America tends to start early and end late in years that begin with warm SSTs in the tropical North Atlantic, and the end dates are also delayed when the eastern equatorial Pacific is cool. This enhancement of date departures for zonally antisymmetric configurations of SSTA between the North Atlantic and Pacific is qualitatively consistent with the results for rainfall anomalies.
\end{abstract}

\section{Introduction}

Enfield (1996) showed that over the large region south of the United States through Central America and the Caribbean and including the northern part of South America at least to the equator, the tropical North Atlantic sea surface temperature anomaly (SSTA) index (NATL) has a comparable coverage of correlations with gridded precipitation anomalies (PCPA) to that of the NINO3 index of SSTA in the eastern equatorial Pacific. This confirms relationships identified in earlier work by Hastenrath $(1978,1984)$ and others. We adopt the term "trade convergence climate complex" (TCCC) to designate this region. Although the correlation between NATL and NINO3 is positive and explains about 25\% of the variance in NATL (Enfield and Mayer 1997), the signs of the correlations for TCCC rainfall with NATL are mostly opposite to those for NINO3 (Enfield 1996). This cannot be easily explained as a false association due to the mutual correlation of Atlantic and Pacific

Corresponding author address: Dr. David B. Enfield, NOAA/Atlantic Oceanographic and Meteorological Laboratory, 4301 Rickenbacker Causeway, Miami, FL 33149-1026.

E-mail: enfield@aoml.noaa.gov
SSTA, and it suggests that the tropical North Atlantic has a unique association with TCCC rainfall and should be accounted for in any regional prediction schemes. It further suggests that when the Atlantic and Pacific SSTAs are of opposite sign the associated rainfall response may be stronger. In this study we have adopted two independent approaches to the analysis of interocean relationships as they relate to rainfall. In the first, we apply a singular value decomposition (SVD) analysis to gridded datasets of monthly SSTA and PCPA as a means of detecting various configurations of Pacific and Atlantic SSTA and their associations with rainfall. In the second, we study the relationship of SSTA indices with the start and end dates of the rainy season over Central America.

\section{Datasets and methods}

The spatial and temporal variabilities of rainfall over the TCCC region are represented by the $2.5^{\circ} \times 2.5^{\circ}$ gridded, hybrid (satellite raingauge model) analysis of Xie and Arkin (1997) for the 1979-95 period. The resolution of the data is better than that of the $5^{\circ} \times 5^{\circ}$ dataset used by Enfield (1996) but it is still coarse enough that inhomogeneities across sharp orographic features are blurred in the analysis. Hence, the results 
obtained here are representative in a large-scale sense but do not reproduce contrasting relationships over small scales where orography may be important. This is true, in particular, between the Pacific and Caribbean sides of the Central American cordillera. The PCPA data were extracted for the TCCC domain, $0^{\circ}-30^{\circ} \mathrm{N}$ and $110^{\circ}-50^{\circ} \mathrm{W}$.

For SSTA the $1950-92$ gridded $\left(2^{\circ} \times 2^{\circ}\right)$ reconstruction of Smith et al. (1996) was updated through 1995 as follows: high-quality, optimally interpolated, and blended (OI) data (satellite and in situ sources) on a $1^{\circ}$ $\times 1^{\circ}$ grid were obtained from the National Centers for Environmental Prediction for 1982-95. As in Smith et al. (1996) the leading 24 empirical orthogonal function (EOF) modes were used to produce a temporally and spatially filtered dataset, which was regridded to $2^{\circ} \times$ $2^{\circ}$ and compared to the Smith et al. data where they overlap (1982-92). That comparison revealed virtually no differences, hence the modified OI data were used to update the Smith et al. data to 1995 and the 197995 period was extracted for analysis with the PCPA data. The SSTA data for this period are mainly interannual in nature and contain no major interdecadal climate shifts such as described by Enfield and Mestas-Nuñez (1999). The SSTA data were extracted for a Western Hemisphere domain that includes both the tropical Atlantic and eastern Pacific Oceans, $40^{\circ} \mathrm{S}-40^{\circ} \mathrm{N}$ and $130^{\circ} \mathrm{W}-20^{\circ} \mathrm{E}$.

To capture possible differences in the SSTA-PCPA relationships between contrasting seasons, the wet and dry seasons of the TCCC region were subjected to separate SVD analyses for the 1979-95 period. A thorough discussion of SVD techniques, examples of their application, and their comparison with other methods can be found in Bretherton et al. (1992) and Wallace et al. (1992). SVD analysis involves an eigenvector decomposition of the cross-covariance matrix between two input fields or variables. When both fields are one and the same variable, the method simply yields an EOF analysis of that variable. As with EOF analysis, SVD analysis decomposes the variability into modes, but in order of decreasing explained crosscovariance between variables rather than of covariance within a single variable field. In each mode a pair of singular vectors describes the spatial patterns of weights or loadings for the two variables that pertain to that mode. Similarly, two series of expansion coefficients describe the weighting of the mode on the two variables in the temporal domain. Closely allied to the singular vectors, but more diagnostic of the spatial relationships between variables, are the heterogeneous correlation maps for each mode. The heterogeneous map for each variable is a plot, over the corresponding spatial domain, of its correlation coefficients for individual grid points against the expansion coefficients of the other variable.

The analysis here considers the relationships of SSTA in both oceans (Pacific and Atlantic) with PCPA over the TCCC domain. The use of both oceans simulta-

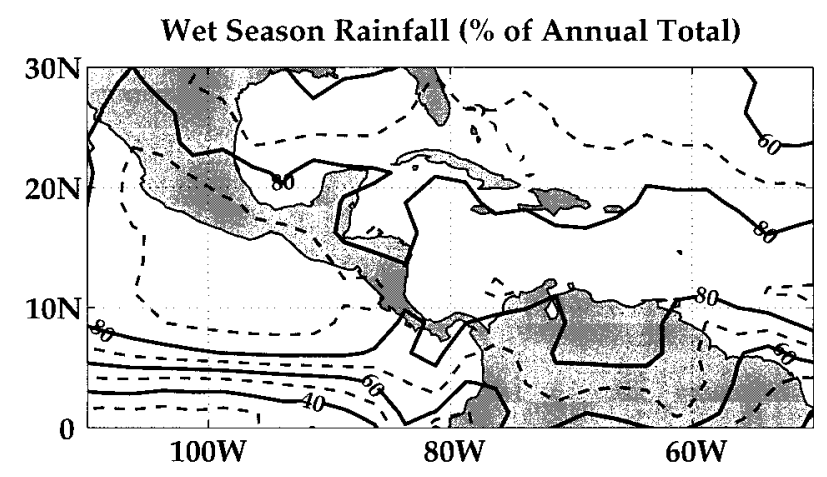

FIG. 1. Percentage of annual rainfall occurring from May through Nov, inclusive.

neously, rather than in separate analyses, takes advantage of the SVD algorithm's ability to isolate a dominant mode of variability that involves covariability of SSTA in both oceans. This is of particular concern because it has been well established by Enfield and Mayer (1997) and others that the Pacific ENSO (as represented by the NINO3 index) has a significant correlation with the SSTA in the tropical Atlantic. Because of this interocean correlation, a separate SVD analysis for one ocean could reveal apparent relationships with rainfall that might instead be whole or partial proxies for relationships involving the other ocean.

Monthly surface wind anomalies from the $2^{\circ} \times 2^{\circ}$ Comprehensive Ocean-Atmosphere Data Set (COADS; Woodruff 1987) were regridded to $2.5^{\circ} \times 2.5^{\circ}$ and vector-correlated with the SVD modal expansion coefficients. The statistical significance of all correlations shown in this paper was determined in a way that accounts for serial correlation in the data by dividing the nominal degrees of freedom by the integral timescale in the combined autocorrelation functions of the compared series (Davis 1976).

\section{Interocean SSTA vs rainfall in the TCCC region}

To determine the rainy or wet season months for the TCCC region, the transition times into and out of the above-median rainy season were mapped over the region. Over most of the region the wet season includes the months of May-November, the notable exception being the equatorial Pacific, where the seasons were reversed. We therefore stratified the data into two periods: May-November and December-April. Henceforth the wet season will refer to the May-November season when TCCC rainfall is highest. We define the rainfall seasonality as the percentage of total annual rainfall that falls during the wet season (Fig. 1). By this measure the seasonality is above $70 \%$ from the midGulf of Mexico southward through Central America, the Caribbean, Venezuela, and most of Colombia. The seasonality is above $80 \%$ over the Caribbean and above 
TABLE 1. Statistics for the first two SVD modes of SSTA vs PCPA, wet and dry seasons. The first section gives the fraction of squared covariance, the normalized squared covariance, and the correlation between left-hand side (SSTA) and right-hand side (PCPA) temporal expansion coefficients. The second and third sections show the correlations between left-hand side and right-hand side coefficients, respectively, and five indices based o area averages of SSTA: NINO3, NATL, SATL, NATL plus SATL (NA + SA), and NATL minus SATL (NA SA). Italicized items are significant at or above the $95 \%$ level.

\begin{tabular}{lrrrr}
\hline \hline & \multicolumn{2}{c}{ Wet season } & & \multicolumn{2}{c}{ Dry season } \\
\cline { 2 - 3 } \cline { 5 - 6 } Mode number & 1 & 2 & 0.0806 & 1 \\
\hline Sq. Cov. Frac. & 0.7350 & 0.0503 & 0.6035 & 0.1571 \\
Nrm. Sq. Cov. & 0.1519 & 0.6213 & 0.1451 & 0.0740 \\
SSTA vs PCPA & 0.8393 & -0.1358 & 0.7868 & 0.5643 \\
SSTA vs NINO3 & 0.9585 & 0.3121 & -0.9542 & -0.3256 \\
SSTA vs NATL & -0.0373 & -0.1819 & -0.4066 & 0.5308 \\
SSTA vs SATL & -0.3167 & 0.0753 & -0.1935 & -0.6923 \\
SSTA vs NA + SA & -0.2334 & 0.3874 & -0.4253 & -0.0733 \\
SSTA vs NA - SA & 0.2283 & 0.0098 & -0.1723 & 0.8702 \\
PCPA vs NINO3 & 0.8155 & 0.1922 & -0.7699 & -0.0307 \\
PCPA vs NATL & -0.0274 & -0.1028 & -0.4142 & 0.3410 \\
PCPA vs SATL & -0.2933 & 0.0525 & -0.0269 & -0.3836 \\
PCPA vs NA + SA & -0.2117 & 0.2311 & -0.3200 & -0.0064 \\
PCPA vs NA - SA & 0.2171 & & -0.2917 & 0.5173 \\
\hline
\end{tabular}
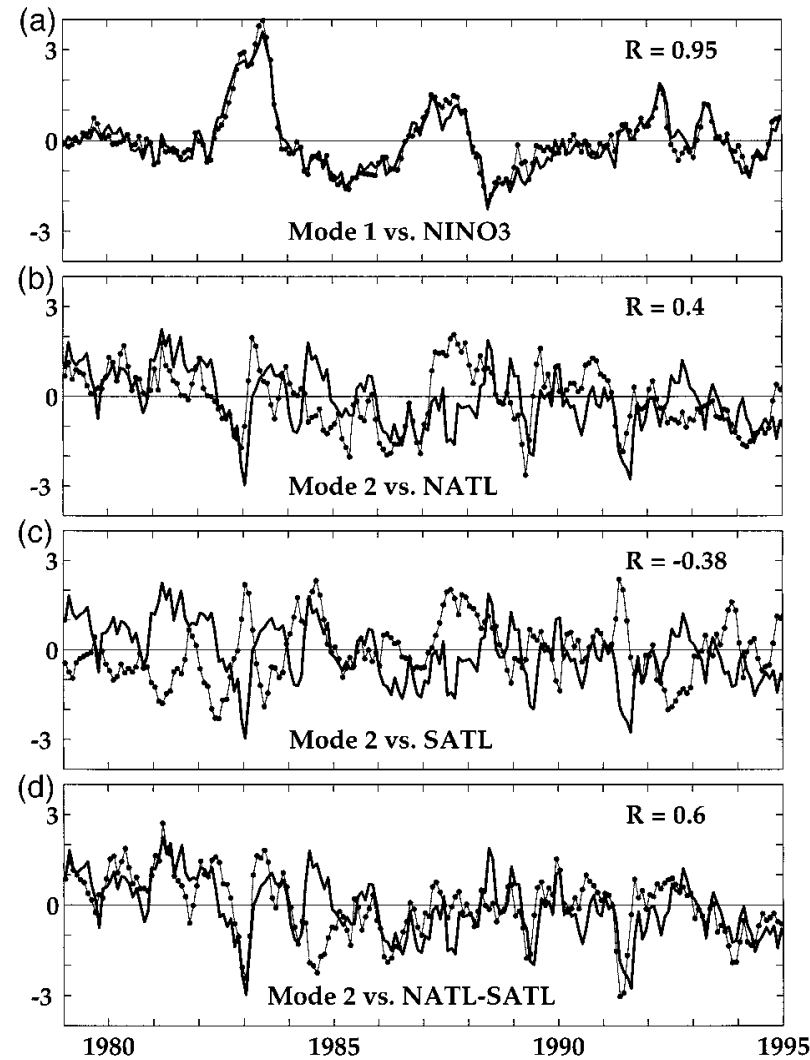

FIG. 2. (a) Combined expansion coefficients for SVD mode 1 (solid curve) and the time series for the NINO3 index of SSTA (dot-solid curve). (b)-(c) Combined expansion coefficients for SVD mode 2 (solid curve) and the respective time series for the NATL, SATL, and NATL-SATL indices of SSTA (dot-solid curves). All series are normalized by their standard deviations. Each panel shows the correlation between the compared series.
90\% along the Pacific margin of Central America and over the eastern North Pacific warm pool, north of the ITCZ. Over the Pacific cold tongue south of about $5^{\circ} \mathrm{N}$ the seasonality is just as sharp but reversed, with the December-April period containing the wettest months.

\section{a. ENSO-related variability (mode 1)}

The basic statistics of the leading two SVD modes (wet and dry seasons) and their relation to ocean SSTA indices are summarized in Table 1 . The normalized SSTA expansion coefficients of the first two modes for the separately analyzed wet and dry seasons are combined and shown in Fig. 2 with the index series for NINO3 (upper panel), with NATL and the South Atlantic SSTA index (SATL) (middle panels), and with the NATL-SATL difference (bottom panel). The SSTA indices are as defined by Enfield (1996): NINO3 $\left(6^{\circ} \mathrm{S}-\right.$ $\left.6^{\circ} \mathrm{N}, 150^{\circ}-90^{\circ} \mathrm{W}\right)$, NATL $\left(6^{\circ}-22^{\circ} \mathrm{N}, 80^{\circ}-15^{\circ} \mathrm{W}\right)$, and SATL $\left(22^{\circ} \mathrm{S}-2^{\circ} \mathrm{N}, 35^{\circ} \mathrm{W}-10^{\circ} \mathrm{E}\right)$. The correlation for each pair of time series is shown in each panel of Fig. 2, and all are above the $95 \%$ level of significance.

The first mode is essentially the ENSO. The NINO3 index and the expansion coefficients for SSTA are virtually identical (Fig. 2), with a correlation of 0.96. By the measure of the squared covariance fraction (SCF; Table 1) the ENSO mode is by far the most important one of the expansion. The SCF statistic is of limited value, however, in judging the degree of overall coupling between the left (SSTA) and right (PCPA) variables, for which the normalized squared covariance (NSC) is more useful (Wallace et al. 1993). The NSC statistic can vary between zero and one. A value of zero indicates no relation between the fields whatsoever, while a value of one means that the variability at each point of one field is everywhere perfectly correlated with the variability of the other field. The NSC statistic 

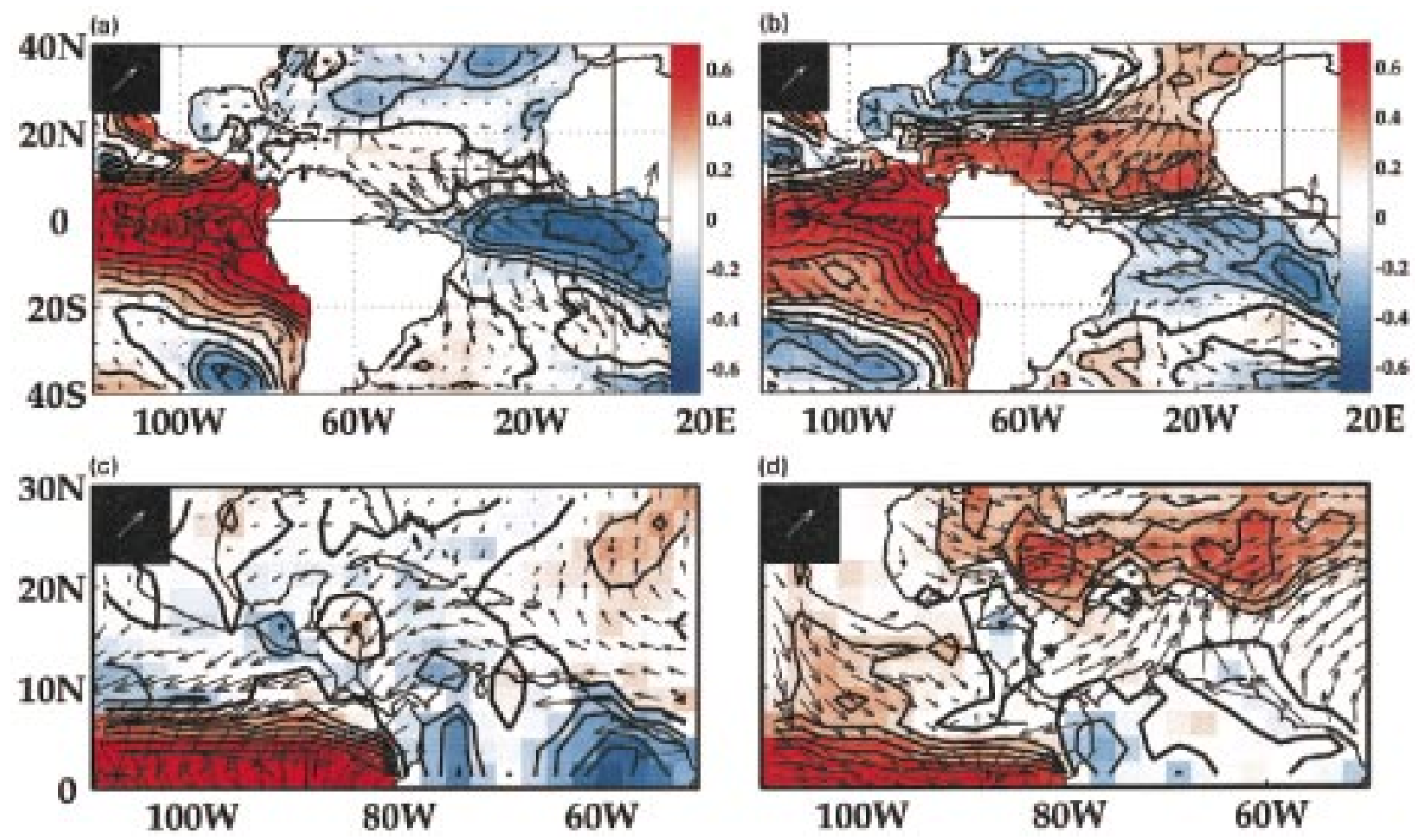

(d)

FIG. 3. Heterogeneous correlation maps for SVD mode \#1. (a),(c) Maps for the wet season and (b),(d) for the dry season. (a),(b) Distribution of scalar correlation (color shading and contours; interval is 0.1) between gridded SSTA data and the mode 1 expansion coefficients for PCPA. Arrows show the vector correlation between the gridded COADS surface wind velocity anomaly and the PCPA expansion coefficients (upper left inset is $0.3 \mathrm{~m} \mathrm{~s}^{-1}$ ). (c),(d) As in (a),(b) but for gridded PCPA vs. the expansion coefficients for SSTA. The average $90 \%$ and 95\% significance levels are 0.17 and 0.20 , respectively.

is domain-dependent and cannot be used to compare the modes of one SVD analysis with those of another analysis using larger or smaller domains. It is, however, an entirely appropriate way to compare the explained covariability between different modes of the same analysis.

The NSC is about 0.15 in both seasons for the first mode. Thus over much of the PCPA grid the rainfall variability is largely unexplained by the SSTA dataset, and vice versa, even in the ENSO mode. During the TCCC wet season only the Pacific NINO3 index is significantly related to the expansion coefficients for either variable. In the dry season, however, lower but significant correlations are also seen with Atlantic variability involving the NATL index. Rather than represent a "non-ENSO" component of variability, we believe that this relates to the relatively high degree of boreal winter connectivity (through a tropospheric bridge effect) between the Pacific ENSO and the tropical North Atlantic SSTA (Enfield and Mayer 1997). This mode, in other words, includes the ENSO-related SSTA variability in the North Atlantic during that season.

The heterogeneous correlation maps for the first mode (Fig. 3) indicate that most of covariability between SSTA and PCPA is concentrated in the eastern equatorial Pacific, with high, positive correlations of 0.60.8 . Consistently, very high amounts of rainfall (relative to normal) occur over this region during the positive phase of ENSO (El Niño). It is this relatively small part of the PCPA grid that accounts for most of the normalized squared covariance.

In the TCCC wet season, the ENSO mode appears connected to an equatorial cooling in the Atlantic, while in the dry season antisymmetric SSTA configurations between the North and South Atlantic across the ITCZ seem to be more important (Figs. 3a and 3b). The importance of the tropical North Atlantic for the dry season is consistent with the ENSO-connected warming described by Enfield and Mayer (1997). They explain this for the NATL region as being primarily due to reduced evaporation and oceanic entrainment associated with weakened northeast (NE) trade winds during the boreal winter. The weakened NE trades can also be seen here in the vector correlations of wind anomalies over the North Atlantic. The anticorrelated SSTA association south of the ITCZ is not a feature of the ENSO teleconnection described by Enfield and Mayer (1997). Instead, this most probably reflects the sensitivity of lowlatitude rainfall (and associated tropospheric properties) to meridional SSTA gradients across the Atlantic ITCZ captured by the SVD (e.g., Nobre and Shukla 1996; Chang et al. 1997).

The PCPA correlations (Figs. $3 \mathrm{c}$ and $3 \mathrm{~d}$ ) are similar 

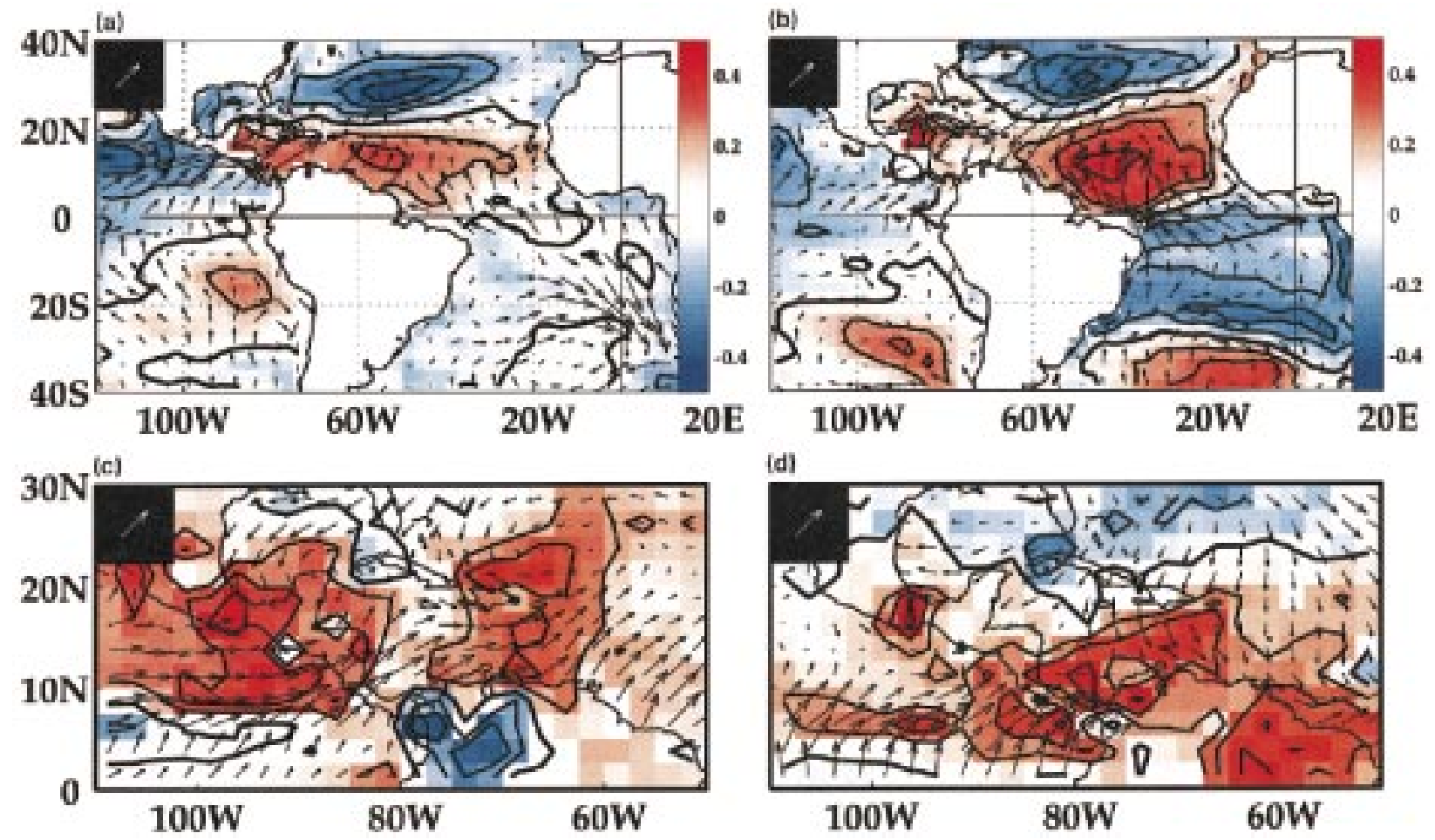

(d)

FIG. 4. As in Fig. 3, for SVD mode 2.

to what one sees when correlating spatially distributed rainfall data with the NINO3 index, and are consistent with the analyses of Ropelewski and Halpert (1987, 1989) and Enfield (1996). Away from the Pacific equatorial cold tongue, strong associated deficits in the wet season rainfall occur over the northern portion of South America, especially in southern Colombia and the Guyanas, and there is a weak (but statistically insignificant) indication of dryness over the Caribbean and Central America. In the dry season excess rainfall tends to occur in a $20^{\circ}-30^{\circ}$ latitude band from the eastern Gulf of Mexico eastward, just north of and bordering the greater Antilles (Cuba, Hispaniola, and Puerto Rico). In both seasons wind anomalies are seen to converge on the equator in the Pacific and are northward across the ITCZ in the Atlantic. The wet season is characterized by westward enhancement of the NE trades in a $10^{\circ}-15^{\circ} \mathrm{N}$ zonal band, with strong anomalous flow across the lower isthmus of Central America. In the dry season, wind anomalies are also significant at higher latitudes, with northerlies south of Mexico and weakened NE trades over the tropical North Atlantic. The easterly flow across the lower isthmus, typically strong at this time of year, is near normal.

\section{b. Atlantic-related variability (mode 2)}

The mode statistics of Table 1 and the heterogeneous correlation maps of Fig. 4 show that the second SVD mode is predominantly an Atlantic-associated mode with an insignificant or marginally significant relation to the NINO3 index. The Atlantic SSTA association is stronger in the dry season and the NSC statistic indicates a stronger overall coupling between SSTA and PCPA in that season, about half that of the ENSO mode. The almost total absence (in Fig. 4) of very strong correlations over the Pacific cold tongue, as seen in the ENSO mode, accounts for the lower NSC in the second (Atlantic) mode. The main features seen in the maps are near the $95 \%$ significance level and the amounts of explained variance (correlation squared) are small even in the regions of maximum correlation. Low values of explained variance in climatic analyses of rainfall are typical, rather than the exception.

As in the first mode, antisymmetry in SSTA across the Atlantic ITCZ is only important in the dry season, when it is part of a pattern of alternating bands that extends to higher latitudes. Again, the low-latitude antisymmetry in SSTA apparently reflects the sensitivity of nearby rainfall variability to the meridional gradients of SSTA and sea level pressure during the dry season. The SSTA features during the wet season are confined north of the equator in both oceans. Both seasons are characterized by zonal asymmetry in SSTA between the Atlantic and Pacific, in the $5^{\circ}-15^{\circ} \mathrm{N}$ band.

In the wet season, with a warm tropical North Atlantic and a cool NE Pacific, there tend to occur significant rainfall surpluses over the eastern North Pacific warm pool and much of Central America and the eastern $\mathrm{Ca}$ ribbean, while rainfall deficits are more likely to occur 
TABLE 2. Statistics for SVD modes 3, 4, and 5 of SSTA vs PCPA, wet and dry seasons, as in Table 1.

\begin{tabular}{|c|c|c|c|c|c|c|}
\hline \multirow[b]{2}{*}{ Mode number } & \multicolumn{3}{|c|}{ Wet season } & \multicolumn{3}{|c|}{ Dry season } \\
\hline & 3 & 4 & 5 & 3 & 4 & 5 \\
\hline Sq. Cov. Frac. & 0.0401 & 0.0352 & 0.0220 & 0.0688 & 0.0421 & 0.0330 \\
\hline Nrm. Sq. Cov. & 0.0355 & 0.0333 & 0.0263 & 0.0490 & 0.0383 & 0.0339 \\
\hline SSTA vs PCPA & 0.6410 & 0.5706 & 0.6350 & 0.6471 & 0.7180 & 0.6009 \\
\hline SSTA vs NINO3 & 0.0159 & 0.2259 & 0.1111 & -0.1479 & 0.1893 & 0.2446 \\
\hline SSTA vs NATL & -0.1528 & 0.7606 & 0.6000 & 0.6377 & -0.0651 & 0.1820 \\
\hline SSTA vs SATL & -0.2301 & 0.4158 & -0.2752 & 0.4011 & 0.3228 & 0.3323 \\
\hline SSTA vs NA + SA & -0.2485 & 0.7532 & 0.1942 & 0.7319 & 0.1673 & 0.3538 \\
\hline SSTA vs NA - SA & 0.0693 & 0.2469 & 0.6483 & 0.2036 & -0.2671 & -0.0907 \\
\hline PCPA vs NINO3 & 0.0001 & 0.1014 & 0.0080 & -0.0536 & 0.1243 & -0.0365 \\
\hline PCPA vs NATL & -0.0396 & 0.3473 & 0.2602 & 0.3411 & 0.0263 & 0.0377 \\
\hline PCPA vs SATL & -0.0751 & 0.1373 & -0.1332 & 0.3438 & 0.1108 & 0.1241 \\
\hline $\mathrm{PCPA}$ vs $\mathrm{NA}+\mathrm{SA}$ & -0.0747 & 0.3090 & 0.0750 & 0.4775 & 0.0929 & 0.1100 \\
\hline $\mathrm{PCPA}$ vs NA - SA & 0.0305 & 0.1554 & 0.3079 & 0.0206 & -0.0559 & -0.0565 \\
\hline
\end{tabular}

over Colombia. In the dry season, with zonally antisymmetric SSTA north of the equator and meridional antisymmetry in the tropical Atlantic, rainfall tends to be high across the lower part of Central America, the southern Caribbean, and east of Venezuela (Guyanas, Surinam, and northern Brazil). In both seasons the rainfall associations over Central America and the Caribbean are much larger than in the first (ENSO) mode.

The vector correlations of surface wind anomalies with the expansion coefficients for SSTA (Figs. 4a and 4b) and PCPA (Figs. 4c and 4d) show a generally weakened easterly wind circulation (westerly anomalies) in the range of the Pacific ITCZ in both seasons, and also south of Mexico during the wet season. In the wet season, the weakened easterly flow also occurs over the eastern Caribbean in association with the greater rainfall there. Wind anomalies are southerly across the equator and ITCZ in both oceans and both seasons, but they are much stronger in the Atlantic during the dry season, in association with the meridional gradient of SSTA.

\section{c. Higher modes}

We show only the statistics for modes 3, 4, and 5 (Table 2) and do not plot their correlation maps because these modes do not prove to be very important for rainfall in the Caribbean or Central American regions. The NSC statistic decreases to $70 \%, 60 \%$, and $50 \%$ of the mode- 2 values for modes 3 , 4, and 5, respectively.

An examination of the correlations of the higher modes with the SSTA indices reveals that modes 3, 4, and 5 are also non-ENSO modes since the expansion coefficients do not correlate significantly with NINO3. This confirms that mode 1 effectively extracts the ENSO-related variability in the data. Only the Pacific SSTA south of $15^{\circ} \mathrm{S}$ is important for the mode-3 wet season (not shown), explaining why none of the chosen indices correlate for that case. In all other cases modes 3, 4, and 5 lack any important relationship with the Pacific SSTA. In particular, none of the modes indicate a strong zonal asymmetry north of the equator, as occurs in mode 2.

The NATL SSTA index shows a large correlation with mode 3 in the dry season and with modes 3 and 4 in the wet season. A symmetric response across the ITCZ $(\mathrm{NA}+\mathrm{SA}$ rather than NA - SA, and where both NATL and SATL are individually significant) occurs for mode 3 (dry season) and mode 4 (wet season). Strong meridional antisymmetry in the SSTA patterns does not occur because the SATL contribution to the mode-5 wet season pattern is weak. The heterogeneous correlation maps for SSTA (not shown) confirm these implications of the SSTA index correlations and show that the North Atlantic is generally stronger in these than the South Atlantic.

The heterogeneous correlation maps for PCPA reveal only small areas of correlation above 0.2 (not shown). These occur in mode 3 over the Guyanas in the dry season and in a $6^{\circ}-12^{\circ} \mathrm{N}$ zonal band west of Central America in the wet season. In mode 4 they occur over Colombia in both seasons. Similarly negative PCPA results hold for mode 5 .

\section{d. Summary of SVD results}

ENSO variability (mode 1) dominated by the Pacific explains the greatest amount of cross covariance between SSTA and PCPA over the domains considered. However, much of the strongly explained variability in rainfall is located over the Pacific Ocean cold tongue, while the only land areas significantly affected are in the northern part of South America where wet season rainfall deficits occur in conjunction with ENSO warmings. These are especially extensive over the Guyanas and projecting eastward and southward into NE Brazil. In the dry season, significant excess rainfall occurs just north of the Caribbean.

The higher SVD modes (modes 2-5) are dominated by Atlantic SSTA patterns and suggest that the tropical North and South Atlantic and the eastern Pacific vary 
widely in the SSTA configurations that they can form, as in a contingency table. Situations must occur when the tropical Atlantic is alternatively in a dipole, a monopole, or a south-only or north-only configuration, whereas the Pacific may be of the same or opposite sign to that of the North Atlantic. The Pacific SSTA associated with the non-ENSO modes are generally weak, however.

Our results for the higher modes (modes 3-5) show that they are of less importance, in general, and over the Caribbean, in particular, than modes 1 and 2. With the exception of mode 3 in the wet season (southeast Pacific), they are only important with respect to Atlantic SSTA and mostly in the North Atlantic. In other words, once the ENSO variability is accounted for, much of the remaining covariance between SSTA and PCPA is accounted for through associations with Atlantic, rather than Pacific SSTA. Unlike mode 2, neither meridional Atlantic antisymmetries nor zonal interocean antisymmetries are important in modes 3,4 , or 5 .

\section{Seasonal transitions over Central America}

In the preceding section we used a seasonally stratified SVD analysis to investigate the associations of the departures of dry and wet season rainfall amounts with SSTA in the Atlantic and Pacific. The results suggest that potentially predictable rainfall situations occur over parts of the Caribbean and Central America when the eastern Pacific and tropical North Atlantic are oppositely signed. They also imply that the tropical North Atlantic is associated with rainfall departures in both seasons, while the South Atlantic is likely to be important mainly for the dry season. In this section we wish to explore the extent to which the transition dates into and out of the rainy season in lower Central America might relate to these same SSTA patterns. This region is comprised primarily of Costa Rica and Panama and was chosen because we have in hand a sufficiently complete coverage (24 stations) of the required daily rainfall amounts for these countries to define such relationships. We also have daily data from 13 rain gauges north of Costa Rica, spread over a larger area. The latter coverage is geographically sparse and therefore the results, which we will mention, may not be conclusive.

To explore these relationships further, we objectively estimated from the 37 Central American daily rainfall series the start dates (SD, typically in April-May) and end dates (ED, typically in November-December) of the sharply defined rainy season. We then correlated the annual date departures with the three SSTA indices for optimally chosen antecedent seasons: December-February (DJF) for NINO3 and February-April for NATL and SATL. These seasons were determined by correlating the SD and ED variates with the SSTA indices for lags varying from one year after to two years prior to the rainy season associated with each occurrence of the variates. At most stations a clear and consistent preference for the chosen seasons was indicated by larger correlations when correlation was plotted in a graph of station versus lag.

The SD/ED estimates themselves are based on pentad (5-day) accumulated from 30-40-yr time series of daily rainfall amounts at the rain gauge stations. All series were taken from the period 1950-94. The most rigorous definition of these dates is the point at which rainfall amounts first exceed (or fall below) the local potential evapotranspiration (Yao 1981). Lacking evaporation data, however, we used a variant of a technique proposed by Amador (1984) and assumed the potential evapotranspiration to be equal everywhere to the regional average, 5-8 $\mathrm{mm}$ day $^{-1}$. The SD is taken to be the time center of the first pentad with $25 \mathrm{~mm}$ or more of rainfall, when at least one of the two succeeding pentads exceeds the same threshold, and the two pentads surrounding or following the latter exceed a trace as a daily average. The ED method is very similar, in reverse, but was modified slightly to account for the fact that the soil is saturated at the end of the rainy season.

The correlations of SD and ED with NINO3 and NATL are shown in Fig. 5. Correlations significant at the $90 \%$ level or greater (larger, filled circles) ranged from 0.25 to 0.48 . In three of the four cases a clear relationship can be seen, evidenced by significant correlations of consistent sign at considerably more stations than can be expected by chance. The mean correlation magnitudes (filled circles) ranged from 0.34 to 0.39 for the three cases: ED/NINO3, SD/NATL, and ED/NATL, such that the typical significance level is actually over the $95 \%$ level of 0.29. A warm (cool) tropical North Atlantic is associated with earlier (later) start dates, later (earlier) end dates, and a longer (shorter) rainy season. A warm (cool) eastern equatorial Pacific is associated with earlier (later) end dates. The fourth case (SD and NINO3) has few significant correlations and its signs are mixed, hence we consider this case to be insignificant.

The correlations with SATL (not shown) do not exhibit full and consistent patterns of significant values such as seen in Fig. 5. By the criteria used for Fig. 5 they are insignificant, as is the SD/NINO3 case. The same is true of the other stations analyzed in northern Central America, but in that case the geographical coverage does not give us the ability to judge spatial patterns of correlation as confidently. Hence we tentatively conclude that the kinds of relationships seen in Fig. 5 do not occur farther north, but this question should probably be revisited when more daily rainfall data are available.

Two points emerge from this analysis. First, the tropical North Atlantic has a greater impact because it affects both the start dates and end dates, while ENSO is associated only with end dates. Second, with respect to the end dates (for which both oceans play a significant role), the Pacific and Atlantic tend to counteract each other when their SSTA is of the same sign, and reinforce each other when they are of opposite sign. This kind of interaction is consistent with the one we see in mode 2 of the SVD analysis for rainfall amounts. We cannot ex- 
(a)

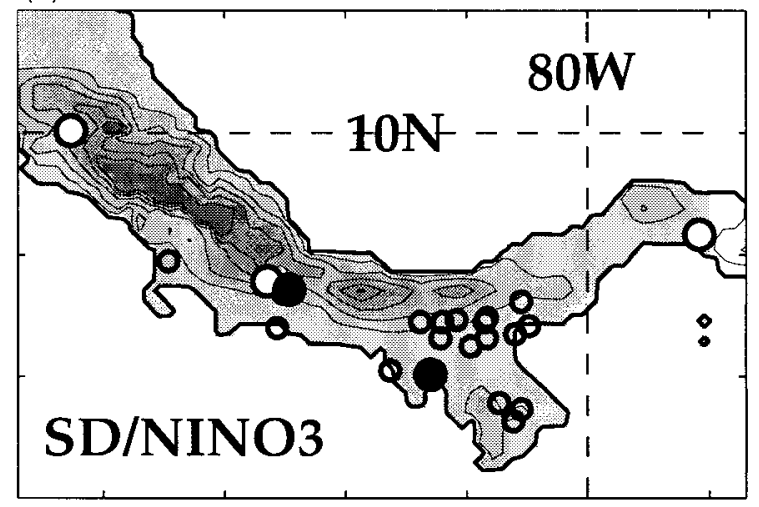

(c)

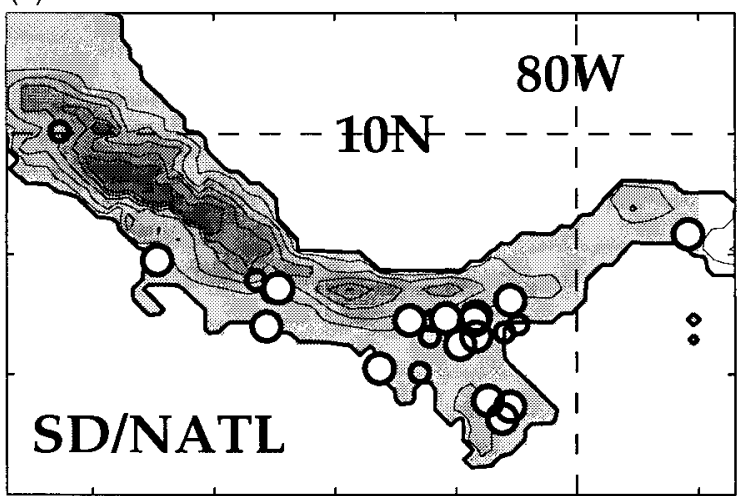

(b)

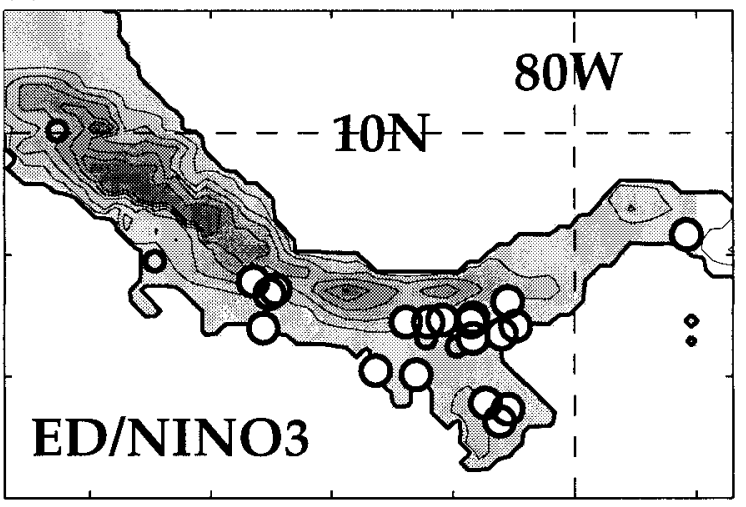

(d)

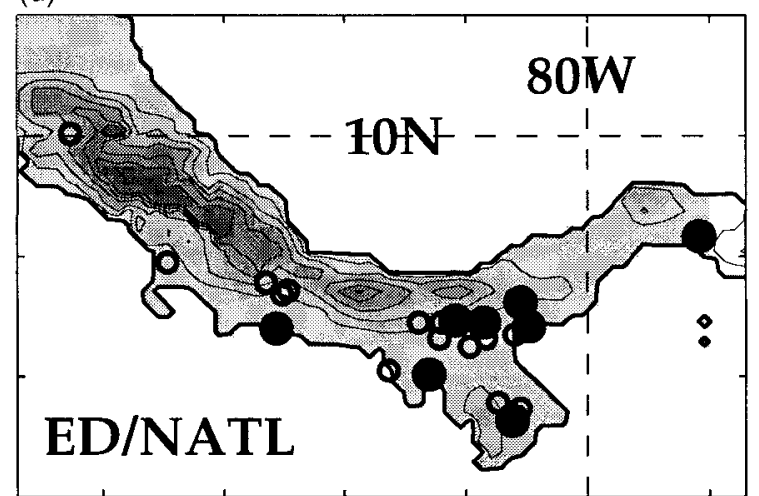

FIG. 5. Categories of correlation for rainy season SD and ED with NINO3 and NATL SSTA indices. Positive (negative) correlation magnitudes of 0.25 or more are indicated as filled black (white) circles. Smaller magnitudes are indicated as smaller, unfilled circles. The 0.25 cutoff value corresponds on average to the $90 \%$ significance level, but the means of the correlations in the significant category are above the $95 \%$ level.

trapolate our conclusions to include the rainfall characteristics on the Caribbean side of the isthmus because the land topography in Fig. 5 shows that all the stations are located on the Pacific side of the central mountain range.

\section{Discussion}

The basic result of this research is that the climate variations of the Caribbean and Central America depend on how the tropospheric structure over this region, and its seasonal march, depend on the interaction of SST variability in both the Atlantic and the Pacific. In this respect we conclude that oppositely signed SST anomalies in the Pacific and tropical North Atlantic are associated with enhanced rainfall departures over the $\mathrm{Ca}$ ribbean and Central America, and an expanded rainy season (contracted dry season) over lower Central America. What follows is a summary and discussion of how each of the two analyses presented relate to these concepts.

\section{a. The SVD analysis}

In the two leading SVD modes the occurrence of significant rainfall anomalies seems to be conditioned by an interplay of anomalous SSTA gradients in the Atlantic or Pacific, or between the two oceans. In both modes, PCPA is associated with strong meridional asymmetry in the Atlantic SSTA during the dry season but not the wet season. When the tropical Atlantic SSTA increases northward strongly, wind anomalies become northward across the Atlantic ITCZ and into the tropical North Atlantic, consistent with a northward shift of the ITCZ. At these times NE Brazil receives less rainfall than normal (e.g., Nobre and Shukla 1996), while Fig. 4 shows there is typically greater than normal rainfall in non-ENSO situations over the Guyanas and eastern Venezuela. This tendency for oppositely signed PCPA between NE Brazil and the Guyanas region is associated with anomalous excursions of the Atlantic ITCZ (Enfield 1996).

The occurrence in the Atlantic of meridional antisymmetry in the two leading SVD modes (dry season) is not an endorsement for the concept of an inherent dipole oscillation in SSTA across the ITCZ. Similar antisymmetric configurations have emerged from other analyses where tropical Atlantic SSTA data are related to nearby rainfall variability (e.g., Moura and Shukla 1981; Nobre and Shukla 1996) or to the tropical Atlantic 
atmosphere (Chang et al. 1997). This happens because such analyses emphasize the highly sensitive relationship that anomalous meridional gradients of SST and sea level pressure (SLP) have with the atmospheric circulation and rainfall in a large region surrounding the Atlantic ITCZ. However, statistical analyses of the SSTA data have shown that the NATL and SATL regions are statistically separable (Houghton and Tourre 1992; Enfield and Mayer 1997). Moreover, dipole configurations occur infrequently and no more often than expected by chance (Enfield et al. 1999). Thus, while dipole configurations can occur and have occurred in the past, they seem to do so randomly rather than in a dynamically coupled sense.

A second non-ENSO feature of dry season rainfall is the occurrence of unusually rainy (dry) conditions over southern Central America and the Caribbean when the North Atlantic is warm (cool) and the Pacific is cool (warm) (mode 2, Fig. 4). Whether or not Atlantic antisymmetry also plays a role in this pattern (which lies fairly far to the west) is unclear; this is not a region that appears to be strongly affected by anomalous excursions of the Atlantic ITCZ (Enfield 1996). In this situation there is a significant weakening (strengthening) of the NE trade winds in the eastern North Pacific, on the northern side of the ITCZ, and eastward into Central America. This is the season when the NE trades are seasonally strong across Central America and the Pacific ITCZ is shifted slightly southward. The normal seasonal dryness is especially marked on the downslope (Pacific) side of the Central American cordillera, aided by the adiabatic descent of air in the trade flow from the Caribbean to the Pacific. Under conditions of weakened $\mathrm{NE}$ trades this orographic effect is probably reduced and the ITCZ is not displaced as far south as normal. However, the excess rainfall shown in Fig. 4 extends both east and west of Central America over a much larger region, transcending what is expected of a purely orographic effect over the isthmus. Thus, while orographic effects may enhance the rainfall response locally over the isthmus, the larger pattern is more consistent with a general weakening of the seasonal tropospheric stability over the region.

One additional feature of the dry season is the occurrence of excess rainfall over a large swath between Florida and the Caribbean during ENSO warm phases (Fig. 3). Because this is the boreal winter and the latitudes are relatively high, we speculate that the excess rainfall is associated with the greater frequency of extratropical cyclone passages across the southern tier of the continental United States that occurs during strong ENSO events. Such storms pick up added moisture as they transit north of the Gulf of Mexico and are known to also produce unusually high winter rainfall over the southeastern United States (e.g., Ropelewski and Halpert 1987).

In the wet season modes 1 and 2 are characterized by zonal asymmetry between the Pacific and Atlantic and with large-scale weakening (strengthening) of the NE trades when the Atlantic is warm (cool) and the Pacific is cool (warm). These same conditions are associated with increased (decreased) rainfall over the Caribbean and Central America, but the rainfall effect is stronger in the non-ENSO variability (Fig. 4) than with ENSO (Fig. 3). In this season and in both modes, the zonal extent of the trade flow anomalies over the Caribbean and Central America is more extensive. The implication is that a generally weaker (stronger) trade flow is associated with a further reduction (increase) of the tropospheric stability during this typically unstable season.

The weakness of the ENSO contribution to rainfall anomalies over the Caribbean and Central America is unexpected. There does occur a large area of insignificant but consistently negative correlations of PCPA with mode 1 , north of $8^{\circ} \mathrm{N}$, but only in the wet season when there is a large-scale strengthening of the NE trade winds from the Atlantic into the Pacific (Fig. 3). In the dry season the NE trades are not affected in this way by ENSO and the correlations are mostly positive, but also insignificant. The association of wet season rainfall deficits with ENSO warm phases over Central America appears qualitatively consistent with the rain gauge analysis of Waylen et al. (1996). However, the Waylen et al. (1996) analysis shows that such relationships are highly constrained by orographic effects on either side of the central cordillera. Less than normal rainfall occurs on the Pacific slopes during ENSO warm phases, with the opposite effects tending to occur on the Caribbean slopes. We therefore interpret the lack of significance to mean that the ENSO-related rainfall effects over Central America tend to be local and significantly affected by orography in conjunction with altered trade wind patterns and that they are poorly resolved by the $2.5^{\circ}$ grid of the Xie and Arkin rainfall data. Orographically induced modifications of the mode 2 pattern are also poorly resolved, but in that case the larger regional scale of the rainfall relationship reflects greater tropospheric instability in general.

One would like to understand why the effect on tropospheric stability is so much weaker in connection with the ENSO cycle. One possible clue is the lack of zonal asymmetry between the Pacific and the tropical North Atlantic during ENSO. In situations such as shown in Fig. 3 (dry season) and Fig. 4 (both seasons), anomalous low SLP develops over the North Atlantic. According to Knaff (1997), high SSTs and low SLPs in the North Atlantic are associated with greater tropospheric moisture and warmer temperatures, weaker 200-850-hPa zonal wind shear, less subsidence, and a weaker tropical upper-tropospheric trough (TUTT) in the Atlantic. The decrease in Atlantic SLP is greater toward the north, away from the equator, so the meridional pressure gradient is decreased. This, in turn, favors persistently weakened northeast trades and persistence of the positive SST anomalies, through evaporation and oceanic entrainment anomalies (Enfield and Mayer 1997). The 
greater instability and weakened vertical shear are consistent with greater deep convection and rainfall in general, and with tropical storm development in particular (Gray 1984). These Atlantic-based characteristics may be a necessary ingredient for extensive rainfall effects to occur over the Caribbean. An anomalous North Atlantic may not be sufficient, however, when the Pacific is also warm, as occurs during ENSO warm phases (especially in the dry season). A warm Pacific, for example, favors increased tropospheric shear, an effect that is so marked during strong El Niño events that Atlantic hurricane frequency is greatly reduced (Gray 1994). This is opposite to what occurs with Atlantic warmings (without regard to the Pacific). Hence, departures of tropospheric characteristics over the Caribbean are apparently enhanced (reduced) when SSTA in the two oceans is of opposite (same) sign. Since most ENSO developments involve associated same-sign anomalies in the Atlantic, our results suggest that rainfall anomalies will tend to be less predictable, which is consistent with the low PCPA correlations over the Caribbean.

It should be added that a recent study by Giannini et al. (1999) using other datasets has confirmed the competition between the eastern Pacific and tropical North Atlantic that we have noted here. Those results are cast in terms of enhancement of rainfall departures by an anomalous (zonal) sea level pressure (SLPA) see-saw between the two basins. This is consistent with our second SVD mode since SLPA and SSTA tend to be locally anticorrelated over each ocean basin.

\section{b. Rainy season onset/end dates}

The most significant result of the analysis of the onset and end dates for the rainy season over lower Central America is that a warm (cool) tropical North Atlantic favors an expansion (contraction) of the rainy season at both ends (onset and end) in southern Central America. There is no evidence that this also occurs north of Costa Rica, however. The correlations are not high, but they are consistent in sign and above $90 \%$ significance at a much greater number of stations than would be expected for purely random correlations. The variance explained in the date anomalies is low, however, so the predictive skill of the relationships may not be high enough to be of practical value for regional climate forecasting unless further research can better isolate the effects. The relationships do not extend to upper Central America and no significant relationships at all were found with the South Atlantic.

The implication of the observed NATL relationships is that the same Atlantic factors that favor increased tropospheric instability and rainfall (Fig. 4) also favor the early development and late demise of the rainy season over lower Central America (Fig. 5). It is perhaps more enlightening, however, to view the NATL effects on the dates as being a contraction of the dry season than an expansion of the wet season (although the dis- tinction is mainly semantic). The SVD mode 2 shows that there is a significantly increased rainfall probability over lower Central America during the dry season when NATL values are above normal, and this is indicative of a generally greater tropospheric instability. This implies that the unstable conditions that develop with the onset of the eastern North Pacific monsoon trough around May can occur earlier because of the already unstable nature of the previous dry season. It is less clear how this mechanism applies to the end dates, however, since the mode 2 analysis is contemporaneous with the dry season prior to the variates analyzed in the analysis of the daily data and not with the succeeding dry season. Moreover, we note that the generally rainier wet season in upper Central America does not result in early onset dates there, as nearly as we can tell from the reduced sample of daily rainfall there.

The NATL index correlations with the rainy season temporal characteristics were done without screening for the coexistence of ENSO anomalies. Hence there exists a possibility that the observed NATL effects are proxies for ENSO influences because of the known connection of some NATL warmings to pre-existing ENSO warmings (Enfield and Mayer 1997). However, the NINO3 index bears no relation to start dates, and the relationship of NINO3 to end dates is opposite to that observed for NATL. Hence it is doubtful that the NATL results have been prejudiced by the existence of ENSO-related variability in the North Atlantic.

The Pacific ENSO variability, represented by the NINO3 index, is significantly related to the rainy season end dates over lower Central America but not to the onset dates. When NINO3 is below normal (equatorial cool events) in DJF, the transition into the following dry season is delayed. This relationship supports in a consistent way what the SVD analysis says about how the climate of this region depends on the mutual configurations of Atlantic and Pacific SSTA. Both a warm tropical North Atlantic and a cool equatorial eastern Pacific associate with end dates in the same way: the rainy season is prolonged. This is the same interocean relationship that results in enhanced rainfall over much of the Caribbean and Central America.

We can only speculate as to why the rainy season onset (May-June) sees no detectable relationship with NINO3, even though ENSO-related anomalies are presumably stronger at that time. This may be due to a seasonal asymmetry in the climatology of the isthmian winds. In the normal onset period winds are already westerly and weak across the isthmus, following the easterly regime of the previous dry season. In November-December easterlies are already in place. The tendency for a warm Pacific to increase easterly flow would make the already easterly winds of November even stronger, discouraging rainfall on the leeward (Pacific) slopes of the isthmus and translating into an earlier dry season onset. The rainy season onset would also see anomalous easterly flow, but since the normal flow in that period is westerly, easterlies 
would not necessarily remain established as a result of the Pacific warm anomalies. In some years rainfall might be affected and in others not, leading to the contradictory correlation pattern observed. If this is true, however, it does not also produce weak onset correlations for the Atlantic SSTA extremes, which must somehow be explained. This may be due to inherent differences in the way the Pacific monsoon trough and the Atlantic TUTT affect the isthmian winds, and it underlines the importance of further research into the tropospheric processes that are involved.

Final remarks are in order for the benefit of those who will inevitably try to leverage these results to obtain improved regional forecasts of rainfall. We have inserted caveats about poorly understood or inconsistent aspects of these analyses and the low levels of explained variance in many of the results. These argue in favor of doing further work to better understand the relationships so that predictability can be improved. Our most useful conclusion for predictive efforts is that oppositely signed SST anomalies in the Pacific and tropical North Atlantic are associated with enhanced rainfall departures over the Caribbean and Central America. This is an inherently more predictable situation, while a same-sign relationship between the oceans implies a less predictable, competitive relationship between the two basins. Thus, when ENSO warm phases develop in a typical manner, with tropical North Atlantic SSTs also becoming warm in the late boreal winter and early spring (Enfield and Mayer 1997), the result in terms of rainfall is likely to be more uncertain. In such situations the relative strength of the anomalies in the Pacific and the Atlantic may be a critical, albeit subjective issue. On the other hand, if zonal asymmetry occurs, especially during the off-years between ENSO events, these relationships may enable forecasts where ENSO-only relationships would be of little help.

Acknowledgments. J. Harris prepared many of the basic datasets used in this project. The daily rainfall data, and useful discussions of date determination, were obtained from J. Amador, with the support of the Centro de Investigaciones Geofisicas, Universidad de Costa Rica, and the Instituto Meteorologico Nacional de Costa Rica. This work has been supported by base funding from the Environmental Research Laboratories, by a grant from the Pan-American Climate Studies (PACS) program, by a grant from the Inter-American Institute for Global Change Research (IAI), and by Universidad de Concepcion Project PI-96112039-6.

\section{REFERENCES}

Amador, J., 1984: Estudio de clima para la Cuenca del Rio Parrita Plan de Manejo de la Cuenca del Rio Parrita. Proyecto GCRAID 515-T-032, Anexos 4 and 5, Sistema Nacional de Areas de Conservacion, 42 pp. [Available from Direccion General Forestal, Ministerio de Agricultura y Ganaderia, Sistema Nacional de Areas de Conservacion, SINAC/MINAE, Apartado 113841000, San Jose, Costa Rica.]

Bretherton, C. S., S. Smith, and J. M. Wallace, 1992: An intercomparison of methods for finding coupled patterns in climatic data. J. Climate, 5, 541-560.

Chang, P., L. Ji, and H. Li, 1997: A decadal climate variation in the tropical Atlantic Ocean from thermodynamic air-sea interactions. Nature, 385, 516-518.

Davis, R. E., 1976: Predictability of sea surface temperature and sea level pressure anomalies over the North Pacific Ocean. J. Phys. Oceanogr., 6, 249-266.

Enfield, D. B., 1996: Relationships of inter-American rainfall to tropical Atlantic and Pacific SST variability. Geophys. Res. Lett., 23, 3305-3308.

, and D. A. Mayer, 1997: Tropical Atlantic SST variability and its relation to El Niño-Southern Oscillation. J. Geophys. Res., 102, 929-945.

_ , and A. M. Mestas-Nuñez, 1999: Multiscale variabilities in global sea surface temperatures and their relationships with tropospheric climate patterns. J. Climate, in press.

- D. A. Mayer, and L. Cid Serrano, 1999: How ubiquitous is the dipole relationship in tropical Atlantic sea surface temperatures? J. Geophys. Res., 104, 7841-7848.

Giannini, A., Y. Kushnir, and M. A. Cane, 1999: Interannual variability of Caribbean rainfall, ENSO and the Atlantic Ocean. $J$. Climate, in press.

Gray, W. M., 1984: Atlantic seasonal hurricane frequency. Part II: Forecasting its variability. Mon. Wea. Rev., 112, 1669-1683.

Hastenrath, S., 1978: On modes of tropical circulation and climate anomalies. J. Atmos. Sci., 35, 2222-2231.

- 1984: Interannual variability and the annual cycle: Mechanisms of circulation and climate in the tropical Atlantic sector. Mon. Wea. Rev., 112, 1097-1107.

Houghton, R. W., and Y. M. Tourre, 1992: Characteristics of lowfrequency sea surface temperature fluctuations in the tropical Atlantic. J. Climate, 5, 765-771.

Knaff, J. A., 1997: Implications of summertime sea level pressure anomalies in the tropical Atlantic region. J. Climate, 10, 789-804.

Moura, A. D., and J. Shukla, 1981: On the dynamics of droughts in northeast Brazil: Observations, theory and numerical experiments with a general circulation model. J. Atmos. Sci., 38, 2653-2675.

Nobre, P., and J. Shukla, 1996: Variations of sea surface temperature, wind stress, and rainfall over the tropical Atlantic and South America. J. Climate, 9, 2464-2479.

Ropelewski, C. F. and M. S. Halpert, 1987: Global and regional scale precipitation patterns associated with the El Niño-Southern Oscillation. Mon. Wea. Rev., 110, 1606-1626.

— and — 1989: Precipitation patterns associated with the high index phase of the Southern Oscillation. J. Climate, 2, 268-284.

Smith, T. M., R. W. Reynolds, R. E. Livezey, and D. C. Stokes, 1996: Reconstruction of historical sea surface temperatures using empirical orthogonal functions. J. Climate, 9, 1403-1420.

Wallace, J. M., S. Smith, and C. S. Bretherton, 1992: Singular value decomposition of wintertime sea surface temperature and 500-mb height anomalies. J. Climate, 5, 561-576.

_ , Y. Zhang, and K. Lau, 1993: Structure and seasonality of interannual and interdecadal variability of the geopotential height and temperature fields in the Northern Hemisphere troposphere. J. Climate, 6, 2063-2082.

Waylen, P. R., M. E. Quesada, and C. N. Caviedes, 1996: Temporal and spatial variability of annual precipitation in Costa Rica and the Southern Oscillation. Int. J. Climatol., 16, 173-193.

Woodruff, S. D., R. J. Slutz, R. L. Jenne, and P. M. Steurer, 1987: A Comprehensive Ocean-Atmosphere Data Set. Bull. Amer. Meteor. Soc., 68, 1239-1250.

Xie, P., and P. A. Arkin, 1997: Global precipitation: A 17-year monthly analysis based on gauge observations, satellite estimates, and numerical model outputs. Bull. Amer. Meteor. Soc., 78, 2539-2558.

Yao, A., 1981: Agricultural Climatology. General Climatology, Vol. 3, World Survey of Climatology, H.E. Landsberg, Ed., Elsevier, 189283. 